\title{
ELECTRONIC INFORMED CONSENT MODEL DEVELOPMENT FOR IMPLEMENTATION IN CLINICAL TRIALS IN UKRAINE
}

\author{
DOBROVA VY, ZUPANETS KO, KOLODYEZNA TY, TIMCHENKO YV \\ Department of Clinical Pharmacology and Clinical Pharmacy, National University of Pharmacy, Kharkiv, Ukraine. \\ Email: clinpharm@nuph.edu.ua
}

Received: 30 June 2017, Revised and Accepted: 01 September 2017

\section{ABSTRACT}

Objectives: The process of signing the informed consent (IC) is one of the essential procedures during organizing and conducting the clinical trial (CT) of any new drug. During this procedure, the volunteers should read the IC form that is often difficult to understand. Analysis of literature showed lack of experience in use of electronic systems in the IC signing in Ukraine. Abroad such systems are quite new. Thus, the aim of this work is the rationale for the introduction of electronic IC to CT drugs in Ukraine and the development of its general model.

Methods: Experience in the use of electronic systems in IC signing analysis was carried out using methods of system analysis, synthesis, abstraction, and generalization.

Results: Thus, during the signing process of paper forms risks and errors may arise such as loss of paper copies and signing of an incorrect version of the document by the volunteer. With the use of electronic forms, it is possible to prevent three categories of risks in preparation and signing, such as risks in the development, use, and auditing of IC forms. The opportunities of the electronic IC system to protect trial subjects in its use during organizing and conducting of CT were showed.

Conclusions: The study showed that such systems are effective. Therefore, it seems appropriate to introduce electronic IC in CT of new drugs in Ukraine. We have formulated requirements to the system and determined its structure for optimal use.

Keywords: Clinical trials, Electronic informed consent, Clinical trial quality management, Risk management.

(C) 2017 The Authors. Published by Innovare Academic Sciences Pvt Ltd. This is an open access article under the CC BY license (http://creativecommons. org/licenses/by/4. 0/) DOI: http://dx.doi.org/10.22159/ajpcr.2017.v10i12.21044

\section{INTRODUCTION}

The process of signing the informed consent (IC) is one of the essential procedures during organizing and conducting the clinical trial (CT) of any new drug, which should provide protection of volunteers' life, health, and well-being [1]. During this procedure, the volunteers should read the IC form and information for a volunteer that is often difficult to understand by future trial participants through a large number of special medical terminology in the text $[2,3]$.

Very often the process of signing the IC is understood as the obtaining of volunteer's signature on paper form $[4,5]$, but in fact in line with international and national requirements the researcher during this process must properly explain all the terms of participation in trial to the volunteer and obtain his/her voluntary consent to participate in CT $[1,6]$.

Signing the IC is the initial stage of any CT and requires special attention and responsibilities of researchers, Ethics Committees and the regulatory authorities because understanding by trial subjects of future CT conditions depends on this procedure conducting, and thus the quality of the obtained during the trial data. Voluntary of IC signing provides observance of ethical norms during the trial because no person shall be compelled to participate in CT of new drugs $[1,6]$.

Technologies are improving every day and frequently infiltrating our lives. Using computer technologies in a proper way can improve data collection, information and quality management [7]. Moreover, computers and computational techniques in drug discovery and development have become popular and widely implemented [8]. Today the research community shows a desire for wider implementation of electronic solutions in practice, in particular, the introduction of electronic IC forms [4].
Analysis of literature showed the lack of experience in the use of electronic systems in the process of IC signing in Ukraine. Abroad such systems are quite new, but already there are developed regulatory requirements and recommendations for their use $[5,9]$. There are the same ethical requirements to the system of electronic IC as to the paper one, that means that they must also protect the rights, health and wellbeing of trial subjects $[4,5,9]$. An important aspect is the voluntary participation of people in CT, and the system of electronic IC can be an effective tool in evaluating this fact with a few simple questions included in its structure.

Thus, the aim of this work is the rationale for the introduction of electronic IC to CT drugs in Ukraine and the development of its general model.

\section{METHODS}

To achieve this goal, the domestic and international experience in the use of electronic systems during signing the IC was analyzed. Processing of the results was carried out using the methods of system analysis, synthesis, abstraction, and generalization.

\section{RESULTS AND DISCUSSION}

Our analysis of the electronic systems in the process of signing the IC use showed that the introduction of electronic IC has many advantages for the various parties, who are involved in the processes of CT of drugs organization and conducting including researchers, trial sponsors/Contract Research Organizations (CRO), trial subjects (volunteers/patients), Ethics Committees, and regulatory authorities (Table 1).

Given the importance of the CT of drugs quality at all stages of management, we have identified potential risks during signing the IC. 
Table 1: The benefits of electronic IC form for the various parties involved in the organization and conducting of CT of drugs

\begin{tabular}{ll}
\hline Advantages of electronic IC & Stakeholder in CT \\
\hline $\begin{array}{l}\text { Reducing costs for monitoring/auditing } \\
\text { Reducing the time for forms and information for patients negotiation } \\
\begin{array}{l}\text { Reducing the amount of participation refusals because of misunderstanding of } \\
\text { the CT conditions }\end{array}\end{array}$ & $\begin{array}{l}\text { Sponsor/CRO, auditors } \\
\text { Sponsor/CRO, researchers } \\
\text { Sponsor/CRO, researchers }\end{array}$ \\
$\begin{array}{l}\text { Accelerate recruitment of volunteers in CT } \\
\text { Sharp control of the current version of the document }\end{array}$ & $\begin{array}{l}\text { Sponsor/CRO, researchers } \\
\text { Sponsor/CRO, researchers, regulatory authorities, Ethics } \\
\text { Committee }\end{array}$ \\
$\begin{array}{l}\text { Reducing the number of errors (improper signing date, no researcher's } \\
\text { signature, incorrect version of the document, etc.) }\end{array}$ & $\begin{array}{l}\text { Sponsor/CRO, researchers, auditors } \\
\text { Reducing the number of volunteers exclusions because of misunderstanding the } \\
\text { conditions during CT }\end{array}$ \\
$\begin{array}{l}\text { The possibility of monitoring the time spent by volunteer to review the } \\
\text { information }\end{array}$ & $\begin{array}{l}\text { Sesearchers, regulatory authorities, Ethics Committee, auditors } \\
\text { Responsive design to features of different CT }\end{array}$ \\
\hline
\end{tabular}

CT: Clinical trial, CRO: Contract research organizations, IC: Informed consent

Thus, during the signing process of paper forms risks and errors may arise such as loss of paper copies, signing of an incorrect version of the document by the volunteer, limited opportunities for inspections and audits, complex for trial subjects understanding content, and so on.

This may lead to participation refusals by volunteers, loss of data, increasing the time required for signing and recruitment of the volunteers to the trial, increased expenses associated with increased control by the sponsor after the procedure performing. Detection of inconsistencies during a clinical audit can lead even to suspend of CT or cancel its research results.

With the use of electronic forms, it is possible to prevent three categories of risks that may arise in the process of preparation and signing, such as risks in the development, use and monitoring/auditing of IC forms.

Risks in the forms development will decrease by controlling the fullness of user access, fixing the sequence of changes and the person who made them, the possibility of locking specific content from alteration or deleting, the ability to install restrictions by sponsor on sending forms for approval to the Ethics Committee or regulatory authorities before his agreement, setting notifications on expecting of review and approval of IC form.

During the monitoring/auditing of the process of signing the use of electronic IC will give the opportunity for permanent at any time remote review of enrolment rate, number of recruited volunteers, see marks of the date and time of signing forms by volunteers, the state of current procedures for signing, and notification settings on need to review the data. Electronic IC will be an up-to-date approval of that fact that any study procedure is initiated after volunteer's consenting, because the date and time of signing cannot be manually shuffled. This remote monitoring/audit of signing procedure will give the opportunity to the sponsor/CRO and auditors to reduce the waste of money and time to review all the signed forms at any required moment and with features of tracking changes and electronic tagging of date and time of signing the forms it will be possible to track the detected errors, fix them effectively and prevent their appearance in the future.

Features of remote monitoring, reviewing and approval of forms by the Ethics Committee, regulatory authorities will significantly reduce costs of time and money should prevent risks and mistakes that are possible when using paper IC forms.

For Ethics Committees, regulatory authorities and volunteers/patients who take part in CT of new drugs, the most important advantage of this system is its increasing of specific medical terms and conditions for future trial understanding by the volunteers/patients are presented in IC forms and information for patients. For this purpose the following instruments in the structure of the electronic IC form system can be used: Tagging of complicated or unclear chapters in IC form that require more attention from the researchers in the further discussion, block of questions to determine the voluntariness of participation in future CT of drugs, tool for evaluation the degree of understanding of the trial in which person wishes to participate conditions by volunteers, which will reduce the amount of refusals due to the lack of understanding of the information received, causing possible acceleration of volunteers recruitment to CT of new drug. This is a factor that will increase the level of trial subjects' health and well-being protection.

For the effective functioning of electronic IC, we can formulate the following basic requirements: The system should be simple to use both for volunteers and for researchers, must be flexible to its quick adaptation to the characteristics of different trials and clinical sites, shall be effective to better support the process of signing and further flow of CT documents.

In our opinion the content of such kind of system should include videos with explanations on basic questions of CT, specific medical terms glossaries that contain clear explanations of medical terms for volunteers, pop-up tips, notifications about any changes in the text, links, and other interactive content that can increase volunteers' understanding of the special trial conditions and medical terminology. It is appropriate to include the electronic form the tools with the help of which volunteers could mark unclear items through the IC form for further discussion with the researcher, since even after the most detailed explanation using interactive content trial subjects may still have questions, the advantage of the electronic system may be just marking the unclear items that require more attention from researchers in the further discussion. In this case, the researcher will be notified of such mark or questions and will know where to begin next meeting with the volunteer.

Thus, it will be possible to achieve the increase of the signing procedure efficiency by individual approach to each volunteer based on their marks in electronic form: Marks of unclear items of IC form, errors in the CT conditions understanding tests and questions that have been left by a volunteer for researchers through a special form in the system.

We offer to ensure the confidentiality of signing process using such a system through the use of personal passwords for volunteers and researchers access to the system. This will allow a volunteer to look through the information form at any convenient time and from any location. On the other hand, the researchers will also be able to watch the volunteers' form review progress, how much time was spent on the reviewing of different parts, the number of times the volunteer went back to some of the issues and at what stage of reviewing the form he/she is currently is. Time spent on exploring the form by volunteer can be used as an indirect indicator of understanding of the IC form and its informative content. 




Fig. 1: The possibilities of electronic informed consent in protection of trial subjects during organizing and conducting clinical trial of drugs

Furthermore, the voluntary participation of individuals in CT is important, so we consider the inclusion of the structure of electronic IC the block of questions to verify this fact as appropriate. The questions of this block should be adapted to the conditions of each individual CT, be simple for volunteers to answer and to determine whether participation of the subject will be voluntary by the content of responses.

Fig. 1 shows the opportunities of the electronic IC system to protect trial subjects in its use during organizing and conducting of CT of drugs. Each component of electronic IC forms should perform the same function as the paper form, but additionally, provides the possibility of a greater degree of control by the researcher for the process of its signing.

To access the degree of volunteers' understanding of information on future CT, we assumed the possibility to include at the request of researchers as one of the electronic system blocks the questions that check volunteers' understanding of CT conditions in which they wish to participate. This will give a complete picture of the degree of understanding by volunteers the future trial conditions and will reduce the amount of refusals due to lack of understanding of the information received, in consequence of which may accelerate the recruitment of volunteers to CT of new drugs.

\section{CONCLUSIONS}

Learning of foreign and domestic experience in the use of electronic systems in the process of signing the IC showed that such systems are effective and reduce the potential risks and errors, helping to save time and money spent on training, implementation and verification process of signing by the volunteers during the participation in CT drugs. Therefore, it seems appropriate to introduce electronic IC in the organization and conducting of CT of new drugs in Ukraine.
We have formulated requirements to the system and determined the structure of its content for optimal use by volunteers and researchers during signing.

In future, it is planned to develop a model of role and place of electronic IC in general electronic flow of documents in CT of drugs, formulate principles which will be used for the implementation of this system, to survey the experts' opinion on the practical application of electronic IC.

\section{REFERENCES}

1. International Conference on Harmonisation of Technical Requirements for Registration of Pharmaceuticals for Human Use. Guideline for Good Clinical Practice. ICH Harmonised Guideline Integrated Addendum to ICH E6 (R1). In: Guideline for Good Clinical Practice E6(R2); 2015. Available from: http://www.ich.org/fileadmin/Public_Web_Site/ICH Products/Guidelines/Efficacy/E6/E6_R2_Addendum_Step2.pdf.

2. Zupanets KO, Dobrova VY, Kolodeznaya TY, Ratushnaya KL. The analysis of compliance with bioethical norms of signing the informed consent in organizing trials of drugs. J Chem Pharm Res 2015;7(11):756-62.

3. Zupanets KO, Dobrova VY, Kolodeznaya TY. Study of the trial subjects protection aspects in Phase I clinical trials and bioequivalence studies. Zaporozhye Med J 2016;2(95):93-7.

4. Litwin J Engagement Shift: Informed Consent in the Digital Era. Applied Clinical Trials Available from: http://www.appliedclinicaltrialsonline. com/engagement-shift-informed-consent-digital-era? pageID $=4$.

5. Use of Electronic Informed Consent: FDA Guidance. Available from: https://www.fda.gov/downloads/drugs/guidances/ucm436811.pdf.

6. Onapproval of Clinical trials and Expertise of Clinical Trials and Model Regulations of the Ethics Committee: Order of Ministry of Health of Ukraine №. 690 From 23.09.2009 (A Sam ended by №. 523 From 12.07.2012, № 304 від 06.05.2014, № 966 From 18.12.2014) Available from: http://www.zakon.rada.gov.ua/cgi-bin/laws/main. cgi?nreg=z1010-09. 
7. Pei LL, Umar II. The application of communication technology in hospital and community pharmacies: A brief review. Int J Pharm Pharm Sci 2015;7(3):1-5.

8. Umashankar V, Gurunathan S. Drug discovery: An appraisal. Int J
Pharm Pharm Sci 2015;7(4):59-66.

9. The Essential Guide to Electronic Informed Consent. Available from: http://www.resources.crfhealth.com/ebooks/the-essential-guide-toelectronic-informed-consent-2. 